\title{
RELATIONSHIP BETWEEN TEXTURE SENSORY PROFILES AND OPTICAL PROPERTIES MEASURED BY TIME-RESOLVED REFLECTANCE SPECTROSCOPY DURING POST-STORAGE SHELF LIFE OF 'BRAEBURN' APPLES
}

\author{
Anna RIZZOLO ${ }^{1}$, Maristella VANOLI ${ }^{1,2}$, Giulia BIANCHI ${ }^{1}$, Angelo ZANELLA $^{3}$, \\ Maurizio GRASSI ${ }^{1}$, Alessandro TORRICELLI ${ }^{2}$, Lorenzo SPINELLI $^{4}$ \\ ${ }^{1}$ Consiglio per la ricerca e sperimentazione in agricoltura, \\ Unità di ricerca per i processi dell'industria agroalimentare, Milano, Italy \\ ${ }^{2}$ Politecnico di Milano, Dipartimento di Fisica, Milano, Italy \\ ${ }^{3}$ Laimburg Research Centre for Agriculture and Forestry, Auer (Ora), BZ, Italy \\ ${ }^{4}$ Istituto di Fotonica e Nanotecnologie CNR, Milano, Italy \\ Received: April 4, 2014; Accepted: June 10, 2014
}

\begin{abstract}
'Braeburn' apples from three harvests after 6-month storage in controlled atmosphere were measured at $670 \mathrm{~nm}$ by time-resolved reflectance spectroscopy (TRS), ranked on decreasing $\mu_{\mathrm{a}} 670$ (increasing maturity), classified as less (LeM), medium and more mature (MoM), randomised into three batches per harvest and analysed after 1, 8 and 14 days of shelf life. LeM and MoM apples were measured in the 630-900 nm range by TRS, and analysed for sensory profile (firm, crispy, juicy, mealy) and pulp mechanical characteristics (firmness, stiffness, energy-to-rupture). All data were processed by Principal Component Analysis (PCA). According to sensory intensity scores, fruits were either divided into five classes (very low - VL; low - L; medium - M; high $-\mathrm{H}$; very high $-\mathrm{VH}$ ) separately for every attribute, or clustered into four groups, each one representing a specific sensory profile. The absorption spectra showed a maximum at $670 \mathrm{~nm}$ (chlorophyll- $a$ ) and $\mu_{\mathrm{a}} 670$ was higher in the $V H$ class for firm, crispy and juicy and in the $V L$ and $L$ classes for mealy. The scattering spectra had a decreasing trend with the wavelength increase, and $\mu_{\mathrm{s}}$ ' values were lower in the $V H$ class for firm and crispy, and higher in the $V H$ class for mealy and in the $V L$ ones for juicy. PCA underlined that $\mu_{\mathrm{s}}$ ' values were negatively related to firmness and $\mu_{\mathrm{a}} 670$, and that $\mu_{\mathrm{a}} 690$, $\mu_{\mathrm{a}} 730, \mu_{\mathrm{a}} 830, \mu_{\mathrm{a}} 850$ and $\mu_{\mathrm{a}} 900$ were opposed to mealiness. PC scores differed among the four sensory profiles and increased from $V L$ to $V H$ classes for firmness, crispiness and juiciness and from $V H$ to $V L$ classes for mealiness.
\end{abstract}

Key words: absorption coefficient, reduced scattering coefficient, texture sensory profiles, pulp mechanical characteristics

\section{INTRODUCTION}

Texture is a key quality attribute for apples and has been considered a multi-parameter attribute that derives from food structure, at molecular, micro- and macro-scale levels (Szczesniak 2002). The sensory attributes that define apple texture are firmness, crispness, juiciness and mealiness; they can be directly evaluated through sensory analysis but the complexity, the high cost and the time consumption of organising panelists and preparing samples limit their use (Chen \& Opara 2013). Thus, numerous studies have been performed to replace sensory analysis with objective instrumental measurements. Good relationships were found between sensory firmness, crispness, crunchiness and a wide range of 
measurements using mechanical techniques (Chen \& Opara 2013; Mehinagic et al. 2003 and 2004). Recently, non-destructive technologies based on fruit optical properties, such as VIS/NIR spectroscopy (Chen \& Opara 2013; Mehinagic et al. 2003 and 2004), hyperspectral scattering images (Huang et al. 2012) and time-resolved reflectance spectroscopy (TRS) have been proposed as tools for apple texture measurements. TRS provides a complete characterisation of diffusive media with the simultaneous measurement of the bulk optical properties, absorption coefficient $\left(\mu_{\mathrm{a}}\right)$ and reduced scattering coefficient $\left(\mu_{\mathrm{s}}{ }^{\prime}\right)$ (Torricelli et al. 2008), up to 1-2 cm depth (Cubeddu et al. 2001) without being significantly affected by surface features (Saeys et al. 2008). TRS has been used to assess fruit maturity and texture in intact fruit (Vanoli et al. 2010). Maturity has been assessed by measuring $\mu_{\mathrm{a}} 670$ (near the chlorophyll- $a$ peak) and classifying high $\mu_{\mathrm{a}} 670$ value of fruits as less mature and those having low $\mu_{\mathrm{a}} 670$ values as more mature (Torricelli et al. 2008). As for apple texture, Rizzolo et al. (2010) reported that in 'Jonagored' apples $\mu_{\mathrm{s}}$ ' 750 and $\mu_{\mathrm{s}}$ ' 780 were positively related to mealy and inversely related to crispy, firm and juicy, and, in correspondence of $\mu_{\mathrm{s}}{ }^{\prime} 780<11 \mathrm{~cm}^{-1}$, only crispy, not mealy apples were found. Moreover, by using both $\mu_{\mathrm{a}}$ and $\mu_{\mathrm{s}}^{\prime}$ 'measured at $650,670,750$ and $780 \mathrm{~nm}$ by TRS, it was possible to discriminate 'Jonagored' apples having a mealy-dry texture without flavour from flavoured apples with a notmealy-juicy texture (Rizzolo et al. 2010), or by using spectral TRS measurements $(670-980 \mathrm{~nm})$, it was possible to correctly classify $98 \%$ of fruits as mealy/non-mealy with mealiness being measured by means of tenderometric parameters (Valero et al. 2005). In 'Braeburn' apples, not mealy fruits were characterised by significantly lower $\mu_{\mathrm{s}}$ ' 790 and $\mu_{\mathrm{s}}$ '912, along with higher values of $\mu_{\mathrm{a}} 912$ (Vanoli et al. 2010).

The aim of this research was to study the relationship between optical properties measured by TRS and apple texture characterised by sensory profiling (firm, crispy, juicy, mealy) and instrumental analysis (firmness, stiffness and energy-torupture) during a 14 days shelf life period after 6 months storage in a controlled atmosphere.

\section{MATERIALS AND METHODS}

'Braeburn' apples were harvested at three times on 29 September (H1), 11 October (H2) and 18 October $(\mathrm{H} 3)$ always from new trees grown at the experimental orchard in Laimburg (Bolzano, Italy) and stored for 6 months at $1.3{ }^{\circ} \mathrm{C}$ in controlled atmosphere $\left(1.5 \% \mathrm{O}_{2}, 1.3 \% \mathrm{CO}_{2}\right)$. At the end of the storage period, 90 fruits per harvest were selected, weighed and measured on two sides by TRS at $670 \mathrm{~nm}$ and ranked within each harvest date on the basis of decreasing $\mu_{\mathrm{a}} 670$ averaged on the two fruit sides (increasing maturity). Ranked fruits of each harvest were divided into 30 groups, corresponding to $30 \mu_{\mathrm{a}} 670$ levels; 10 less mature (LeM, batch ranks 1-10); 10 medium mature; 10 more mature (MoM, batch ranks 21-30) TRS maturity classes. Fruits from every group were randomised into three batches in order to have fruits from the whole range of $\mu_{\mathrm{a}} 670$ in each sample. The three batches were randomly assigned to three times of analysis during a shelf life period of 14 days (after 1,8 and 14 days at $20^{\circ} \mathrm{C}$ ). At each time of analysis, TRS optical properties in the 630-900 nm range were measured on LeM and MoM apples on two opposite sides (the blush side and the opposite one) and data were averaged per fruit.

On the same fruit, physical (mass, firmness, stiffness, energy-to-rupture $\left.\left(E_{\mathrm{f}}\right)\right)$ and sensory analyses (firmness, crispiness, juiciness, mealiness) were carried out. TRS measurements were performed using a set-up developed by Politecnico di Milano (details can be found in Vanoli et al. 2013). A model for photon diffusion in turbid media was used to analyse TRS data to assess $\mu_{\mathrm{a}}$ and $\mu_{\mathrm{s}}$ ' of samples (Martelli et al. 2009). An approximation to the Mie theory was used to relate the $\mu_{\mathrm{s}}$ ' to the structural properties of the diffusive sample: $\mu_{\mathrm{s}}{ }^{\prime}=A\left(\lambda / \lambda_{0}\right)^{-B}$, where $\lambda$ is the wavelength, $A$ is the scattering coefficient at wavelength $\lambda_{0}=600 \mathrm{~nm}$ and $B$ is a parameter related to the size of scatterers.

Firmness was measured with an 11-mm diameter plunger mounted on an Instron Universal Testing Machine Model 4301 (Instron Ltd., High Wycombe, UK) with crosshead speed of $200 \mathrm{~mm} \cdot \mathrm{min}^{-1}$ to a depth of $8 \mathrm{~mm}$ on two peeled areas (blush and opposite side) per fruit. The applied force was recorded. From the force-displacement curve the following variables 
were recorded: flesh firmness $(F)$, stiffness $(S t)$ and energy-to-rupture $\left(E_{\mathrm{f}}\right)$ according to Mehinagic et al. (2003). Firmness, stiffness and energy-to-rupture readings were averaged for each fruit.

Sensory analyses were carried out with the aid of a panel of 10 short-term-trained judges comparing apples of the LeM and MoM TRS classes coming from the three harvests. In each session, one peeled slice per fruit of LeM and MoM classes from each harvest date, coded with three digit random numbers were presented to each panelist. In order to have the same differences in maturity $\left(\mu_{\mathrm{a}} 670\right)$ among fruits for all the 10 assessors, fruit presented to each panelist had the same rank position in the samples. At the beginning of each session, a slice of a fruit not included in the experimental plan was tasted to eliminate the first tasting effect. Each sample was evaluated for the intensity of attributes related to fruit structure: firm, crispy, juicy and mealy using $120 \mathrm{~mm}$ unstructured line scales with anchors at $12 \mathrm{~mm}$ from the extremes (low, high).

Prior to statistical analyses, the rating scores of each attribute were standardised by panelist according to Bianchi et al. (2009) in order to remove the variability due to panelists using different parts of the scale. ANOVA, principal component analysis (PCA) and cluster analysis were performed using Statgraphics ver. 7 (Manugistics Inc., Rockville, MD, USA) software package. According to sensory intensity scores, fruits were either divided into five classes (<20: very low - VL; 21-39: low - L; 40-59: medium - M; 60-80: high $-\mathrm{H} ;>80$ : very high $-\mathrm{VH}$ ) separately for every attribute, or clustered into four groups, each one representing a specific sensory profile, applying the Ward's clustering method and squared Euclidean distance. Data of weight loss during shelf life, mechanical and sensory characteristics and of optical properties were processed together by PCA on variance matrix. TRS optical properties, physical and sensory data and principal components (PC) scores were submitted to ANOVA considering as factor either the five classes of intensity for each attribute or the four clusters (means compared by Bonferroni's test at $\mathrm{p} \leq 0.05$ ).

\section{RESULTS AND DISCUSSION}

The combination of three harvest times with the post-storage shelf life at $20{ }^{\circ} \mathrm{C}$ up to 14 days allowed us to obtain a wide range of texture characteristics. In fact, it has been reported for the fruits used in this experiment (Vanoli et al. 2013) that the apples of the first harvest and belonging to the LeM TRS maturity class showed the highest firmness, stiffness and $E_{\mathrm{f}}$ and the highest scores for sensory firmness, crispness and juiciness. Furthermore, the same authors reported that the extent of softening and the changes in stiffness, $E_{\mathrm{f}}$ and sensory properties bound to texture achieved with shelf life depended on both harvest date and TRS maturity class.

Fig. 1 shows the results of the application of cluster analysis on the sensory variables. From an exploratory analysis carried out by dividing the standard score of each attribute into five classes according to the intensity of the attribute, and by pairing the classes of all attributes for every sample, it was found that the minimum number of combinations of intensity classes between attributes was four.

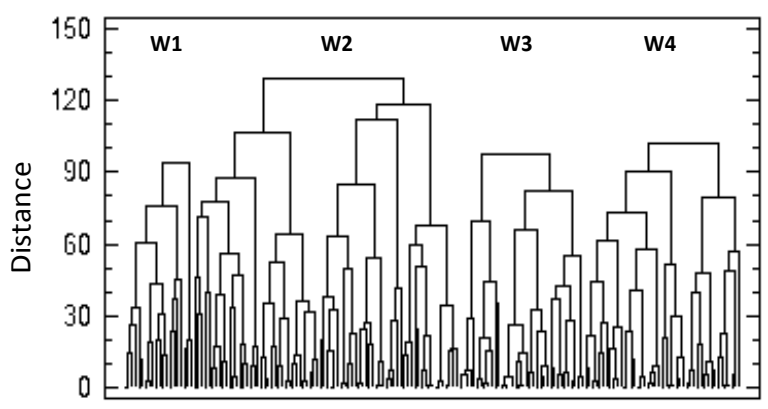

Fig. 1. Classification dendrogram (cluster analysis on sensory variables) of 'Braeburn' apples. Codes W1 to W4 refer to profiles in Table 1

Table 1. Sensory profiles of the four clusters. For each cluster are reported: the description of the sensory profile, the values of centroids for each descriptor, and the number of observations $\left(N_{\text {obs }}\right)$ grouped in the cluster

\begin{tabular}{lcrrrc}
\hline \multicolumn{1}{c}{ Cluster number and sensory profile } & firm & crispy & mealy & juicy & $N_{\text {obs }}$ \\
\hline W1 - very soft and very mealy, not juicy, not crispy & 26.98 & 34.78 & 102.28 & 24.38 & 20 \\
W2 - firm/crispy/juicy and quite mealy & 67.06 & 62.73 & 51.22 & 65.24 & 76 \\
W3 - very firm, very crispy and juicy, not mealy & 87.68 & 93.28 & 34.94 & 87.39 & 36 \\
W4 - quite firm/crispy/juicy and mealy & 42.07 & 41.45 & 74.33 & 46.66 & 45 \\
\hline
\end{tabular}



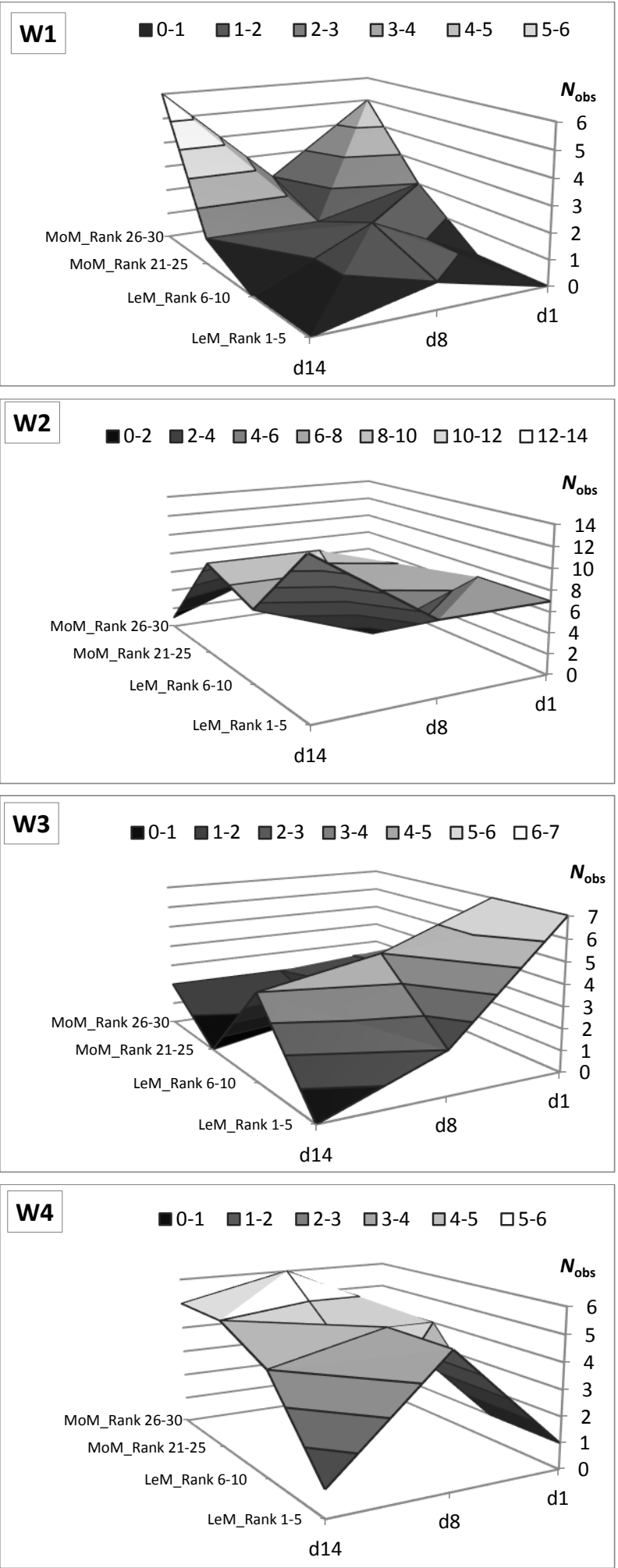

Fig. 2. Number of fruits $\left(N_{\mathrm{obs}}\right)$ of LeM_Rank 1-5, LeM_Rank 6-10, MoM_Rank 21-25 and MoM_Rank 26-30 maturity classes after 1 (d1), 8 (d8) and 14 (d14) days of shelf life at $20^{\circ} \mathrm{C}$ grouped in $\mathrm{W} 1$ to $\mathrm{W} 4$ sensory profiles
Hence, cluster analysis was applied with the aim of grouping all apple fruits considered in this experiment into four clusters, each one having a distinctive texture profile. Each cluster corresponds to a specific sensory texture profile according to the descriptions and centroids values reported in Table 1. Fig. 2 shows for each cluster the number of fruits at 1,8 and 14 days of shelf life belonging to LeM and MoM maturity classes, which were divided into two sub-sets according to ranking position in order to distinguish the least mature fruits, which are grouped in the LeM_Rank 1-5 sub-set, and the most mature ones, grouped in the MoM_Rank 26-30 sub-set. Under the W1 sensory profile were grouped the most soft and mealy, not juicy and not crispy apples (harvests: H1: 5\%; H2: 40\%; H3: 50\%) which mainly belonged to MoM_Rank 26-30 class both at day 1 and day 14 of shelf life. In profile W2 were grouped about $43 \%$ of analysed fruits (H1: 42\%; H2: 33\%; H3: 25\%) which were characterised by a firm, crispy, juicy and quite mealy texture and mainly belonging to LeM class and MoM_Rank 20-25 after 8 and 14 days at $20^{\circ} \mathrm{C}$. Under the sensory profile $\mathrm{W} 3$ were grouped the most firm, crispy and juicy apples (H1: 53\%; H2: 19\%; H3: $28 \%$ ), which mainly belonged to LeM class at day 1 of shelf life. Apples (H1: 16\%; H2: 42\%; H3: 42\%) of LeM_Rank 6-10 and MoM class mainly after 8 days of shelf life were grouped under sensory profile W4, described as quite firm/crispy/juicy and mealy.

The pulp optical properties and the mechanical characteristics significantly changed according to sensory intensity class for each attribute as well as to the sensory profiles obtained by cluster analysis.

The absorption spectra (Fig. 3, left) showed a maximum at $670 \mathrm{~nm}$ (chlorophyll- $a$ ); $\mu_{\mathrm{a}} 670$ was significantly higher for W2 and W3 sensory profiles and in the VH class for firm, crispy and juicy and in the VL and L classes for mealy (Table 2). The scattering spectra (Fig. 3, right) had a decreasing trend with the wavelength increase; the B parameter, related to size of scatterers, was (mean \pm standard error) $0.118 \pm 0.007$ and did not change with sensory intensity class for each attribute as well as with the W1-W4 sensory profiles obtained by cluster analysis, whereas parameter $\mathrm{A}$ was lower in the VH class for firm and $\mathrm{H}$ and $\mathrm{VH}$ classes for juicy, and higher in the VL, L and M classes for firm and in the VL ones for juicy (Table 2). 

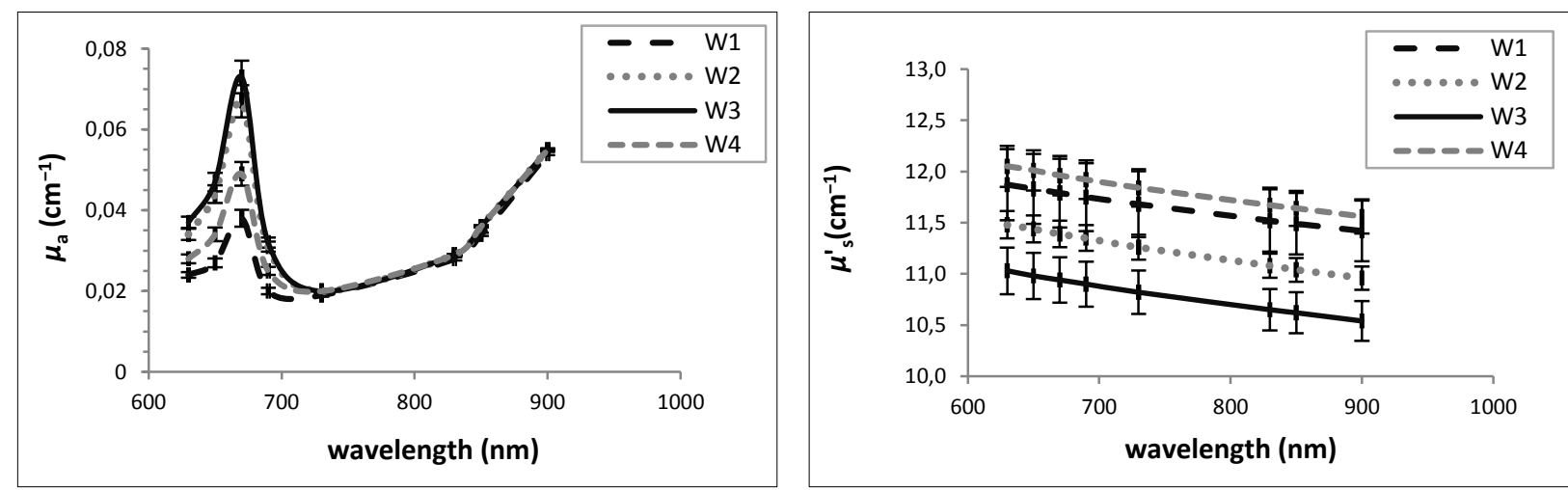

Fig. 3. Absorption (left) and scattering (right) spectra of apples grouped in the W1 to W4 sensory profiles. Bars refer to standard error

Table 2. Absorption coefficient at $670 \mathrm{~nm}\left(\mu_{\mathrm{a}} 670\right)$, scattering parameter A, sensory scores, mechanical properties $(F$, firmness; $S t$, stiffness; $E_{\mathrm{f}}$, energy-to-rupture), weight loss in shelf life (WL) and number of observations ( $\left.N_{\mathrm{obs}}\right)$ grouped in the five intensity classes of firm, crispy, juicy and mealy sensory profile. Within each sensory descriptor means in the same column followed by different letters are statistically different (Bonferroni's test, $\mathrm{p} \leq 0.05$ )

\begin{tabular}{|c|c|c|c|c|c|c|c|c|c|c|}
\hline \multirow{2}{*}{$\begin{array}{l}\text { Class } \\
\left(N_{\text {obs }}\right)\end{array}$} & \multirow{2}{*}{$\begin{array}{l}\mu_{\mathrm{a}} 670 \\
\left(\mathrm{~cm}^{-1}\right)\end{array}$} & \multirow{2}{*}{$\begin{array}{c}\mathrm{A} \\
\left(\mathrm{cm}^{-1}\right)\end{array}$} & \multicolumn{4}{|c|}{ Sensory scores } & \multirow{2}{*}{$\begin{array}{c}F \\
(\mathrm{~N})\end{array}$} & \multirow{2}{*}{$\begin{array}{c}S t \\
(\mathrm{~N} / \mathrm{mm})\end{array}$} & \multirow{2}{*}{$\begin{array}{c}E_{\mathrm{f}} \\
(\mathrm{mJ})\end{array}$} & \multirow{2}{*}{$\begin{array}{l}\text { WL } \\
(\%)\end{array}$} \\
\hline & & & $\mathrm{F}^{*}$ & $\mathrm{C}^{* *}$ & $\mathbf{M}^{* * *}$ & $\mathbf{J}^{* * * * *}$ & & & & \\
\hline \multicolumn{11}{|c|}{ FIRM Profile } \\
\hline VL(7) & $0.034 \mathrm{c}$ & $12.65 \mathrm{a}$ & $14.0 \mathrm{e}$ & $28.1 d$ & $101.5 \mathrm{a}$ & $23.2 \mathrm{c}$ & $46.6 c$ & $16.6 \mathrm{~d}$ & $34.8 \mathrm{c}$ & $2.84 \mathrm{a}$ \\
\hline $\mathrm{L}(35)$ & $0.048 b c$ & $12.16 \mathrm{a}$ & $31.5 \mathrm{~d}$ & $37.4 \mathrm{~d}$ & $84.5 \mathrm{a}$ & $46.3 b c$ & $51.1 \mathrm{c}$ & $19.1 \mathrm{~cd}$ & $45.7 b c$ & $1.24 \mathrm{bc}$ \\
\hline $\mathrm{M}(46)$ & $0.049 \mathrm{c}$ & $11.81 \mathrm{a}$ & $49.8 c$ & $49.3 c$ & $66.1 b$ & $53.1 \mathrm{~b}$ & $53.8 \mathrm{c}$ & $20.7 b c$ & $47.8 b c$ & $1.56 \mathrm{~b}$ \\
\hline $\mathrm{H}(47)$ & $0.064 b$ & $11.54 \mathrm{ab}$ & $71.0 \mathrm{~b}$ & $68.1 b$ & $47.1 \mathrm{c}$ & $67.8 \mathrm{a}$ & $58.2 \mathrm{~b}$ & $22.3 \mathrm{ab}$ & $53.0 \mathrm{ab}$ & $1.24 b c$ \\
\hline $\mathrm{VH}(42)$ & $0.085 \mathrm{a}$ & $11.01 \mathrm{~b}$ & $91.8 \mathrm{a}$ & $88.5 \mathrm{a}$ & $38.5 \mathrm{c}$ & $78.0 \mathrm{a}$ & $65.0 \mathrm{a}$ & $24.0 \mathrm{a}$ & $56.4 \mathrm{a}$ & $0.84 \mathrm{c}$ \\
\hline \multicolumn{11}{|c|}{ CRISPY Profile } \\
\hline VL(3) & $0.040 \mathrm{ab}$ & $13.22 \mathrm{a}$ & $10.7 \mathrm{e}$ & $9.4 \mathrm{e}$ & $119.1 \mathrm{a}$ & $6.2 \mathrm{~d}$ & $44.0 \mathrm{c}$ & $15.3 \mathrm{c}$ & $34 \mathrm{ab}$ & $2.63 \mathrm{a}$ \\
\hline $\mathrm{L}(37)$ & $0.049 \mathrm{~b}$ & $12.10 \mathrm{a}$ & $37.4 d$ & $32.4 \mathrm{~d}$ & $82.0 \mathrm{~b}$ & $45.6 \mathrm{c}$ & $51.6 \mathrm{c}$ & $19.6 b c$ & $44 b$ & $1.35 \mathrm{a}$ \\
\hline $\mathrm{M}(50)$ & $0.054 b$ & $11.68 \mathrm{a}$ & $51.2 \mathrm{c}$ & $48.3 \mathrm{c}$ & $63.8 \mathrm{c}$ & $58.4 \mathrm{~b}$ & $54.3 \mathrm{bc}$ & $20.9 b$ & $49 \mathrm{ab}$ & $1.42 \mathrm{a}$ \\
\hline $\mathrm{H}(43)$ & $0.063 \mathrm{ab}$ & $11.48 \mathrm{a}$ & $67.4 b$ & $68.1 b$ & $54.8 \mathrm{c}$ & $61.3 b$ & $56.7 b$ & $21.2 b$ & $52 \mathrm{ab}$ & $1.48 \mathrm{a}$ \\
\hline $\mathrm{VH}(44)$ & $0.077 \mathrm{a}$ & $11.29 \mathrm{a}$ & $86.7 \mathrm{a}$ & $93.5 \mathrm{a}$ & $36.5 \mathrm{~d}$ & $77.8 \mathrm{a}$ & $65.0 \mathrm{a}$ & $24.2 \mathrm{a}$ & $57 \mathrm{a}$ & $0.81 b$ \\
\hline \multicolumn{11}{|c|}{ MEALY Profile } \\
\hline VL(3) & $0.080 \mathrm{ab}$ & $10.74 \mathrm{a}$ & $97.3 \mathrm{a}$ & $97.8 \mathrm{a}$ & $20.0 \mathrm{e}$ & $106.4 \mathrm{a}$ & 61.6abc & $23.8 \mathrm{ab}$ & $38.7 \mathrm{abc}$ & $0.60 \mathrm{ab}$ \\
\hline $\mathrm{L}(44)$ & $0.072 \mathrm{a}$ & $11.21 \mathrm{a}$ & $80.6 \mathrm{a}$ & $83.6 \mathrm{a}$ & $33.7 \mathrm{~d}$ & 74.0ab & $63.1 \mathrm{a}$ & $23.4 \mathrm{a}$ & $56.7 \mathrm{a}$ & $0.95 b$ \\
\hline $\mathrm{M}(52)$ & $0.069 \mathrm{a}$ & $11.71 \mathrm{a}$ & $68.9 b$ & $65.1 b$ & $49.5 c$ & $64.7 b c$ & $58.0 \mathrm{~b}$ & $22.1 \mathrm{ab}$ & $53.4 \mathrm{ab}$ & $1.34 \mathrm{ab}$ \\
\hline $\mathrm{H}(40)$ & $0.052 b$ & $11.80 \mathrm{a}$ & $50.9 \mathrm{c}$ & $48.8 \mathrm{c}$ & $69.9 b$ & $54.0 \mathrm{~cd}$ & $54.5 b$ & $21.0 \mathrm{~b}$ & $45.5 b c$ & $1.42 \mathrm{ab}$ \\
\hline $\mathrm{VH}(38)$ & $0.044 \mathrm{~b}$ & $11.99 \mathrm{a}$ & $32.3 \mathrm{~d}$ & $36.3 \mathrm{~d}$ & $95.5 \mathrm{a}$ & $42.3 \mathrm{~d}$ & $49.9 \mathrm{c}$ & $18.5 \mathrm{c}$ & $44.6 \mathrm{c}$ & $1.54 \mathrm{a}$ \\
\hline \multicolumn{11}{|c|}{ JUICY Profile } \\
\hline VL(8) & $0.052 \mathrm{ab}$ & $13.18 \mathrm{a}$ & $28.4 d$ & $34.1 \mathrm{c}$ & $93.6 \mathrm{a}$ & $12.4 \mathrm{e}$ & $50.5 b c$ & $18.1 b$ & $39.7 b$ & $1.83 \mathrm{a}$ \\
\hline $\mathrm{L}(31)$ & $0.045 b$ & $11.57 \mathrm{~b}$ & $43.9 \mathrm{~cd}$ & $47.0 \mathrm{c}$ & $75.1 \mathrm{ab}$ & $31.9 \mathrm{~d}$ & $52.3 \mathrm{c}$ & $19.5 b$ & $47.5 \mathrm{ab}$ & $1.51 \mathrm{a}$ \\
\hline $\mathrm{M}(50)$ & $0.062 \mathrm{ab}$ & $11.92 \mathrm{ab}$ & $57.1 b c$ & $55.8 \mathrm{bc}$ & $65.5 b$ & $50.0 \mathrm{c}$ & $55.9 \mathrm{bc}$ & $21.3 \mathrm{ab}$ & $47.7 \mathrm{ab}$ & $1.28 \mathrm{a}$ \\
\hline H(49) & $0.062 \mathrm{ab}$ & $11.57 \mathrm{~b}$ & $65.6 \mathrm{ab}$ & $62.9 \mathrm{~b}$ & $49.8 \mathrm{c}$ & $71.4 b$ & $58.1 \mathrm{ab}$ & $21.9 \mathrm{a}$ & $54.6 \mathrm{a}$ & $1.32 \mathrm{a}$ \\
\hline VH(39) & $0.070 \mathrm{a}$ & $11.15 \mathrm{~b}$ & $77.7 \mathrm{a}$ & $79.1 \mathrm{a}$ & $44.9 \mathrm{c}$ & $92.4 \mathrm{a}$ & $61.2 \mathrm{a}$ & $23.2 \mathrm{a}$ & $54.5 \mathrm{a}$ & $0.99 \mathrm{a}$ \\
\hline
\end{tabular}

$\mathrm{F}^{*}$ - firmness; $\mathrm{C}^{* *}-$ crispness; $\mathrm{M}^{* * *}-$ mealiness; $\mathrm{J}^{* * * *}-$ juiciness 
Considering the sensory profiles, parameter A, related to the density of scatterers, was higher for $\mathrm{W} 4$ profile and lower for $\mathrm{W} 3$ ones, being on average (mean \pm standard error) $11.93 \pm 0.35,11.56 \pm 0.14$, $11.10 \pm 0.23$ and $12.12 \pm 0.20 \mathrm{~cm}^{-1}$ for W1, W2, W3 and W4 sensory profiles, respectively. Scattering parameters suggest that the sensory intensity classes and the sensory profiles were characterised by scatters of equal size but of different densities.

Considering the pulp mechanical properties and the weight loss during shelf life in function of the intensity classes of the four sensory attributes (Table 2), the highest values of firmness, stiffness and $E_{\mathrm{f}}$ were found for apples belonging to $\mathrm{VH}$ intensity class for firm, crispy and juicy, and for those of $\mathrm{L}$ and VL intensity classes for mealy. The M, L and VL intensity classes of firm, crispy and juicy did not differ for firmness and $E_{\mathrm{f}}$, but firm $\mathrm{M}$ class showed higher stiffness than the VL ones, the L and VL classes of crispy had lower stiffness than the M and $\mathrm{H}$ classes, whereas the $\mathrm{VH}$ and $\mathrm{H}$ classes of juiciness were characterised by higher stiffness than the $\mathrm{L}$ and VL ones. As for the mechanical properties, for the mealy intensity classes firmness and stiffness of the VH class were lower than the $\mathrm{M}$ and $\mathrm{H}$ ones, while $E_{\mathrm{f}}$ of the $\mathrm{L}$ mealy class was higher than the $\mathrm{H}$ and $\mathrm{VH}$ ones. Weight loss during shelf life was significantly lower in VH class for firm and crispy and higher in $\mathrm{VH}$ class for mealy.

Considering the mechanical properties and weight loss during shelf life of the apples grouped in the W1-W4 sensory profiles (Fig. 4), as expected the very mealy fruit of profile W1 were characterised by the least firmness and stiffness and the highest weight loss, whereas the most crispy and juicy fruit clustered into profile W3 showed the highest firmness and the least weight loss, and higher values of stiffness and $E_{\mathrm{f}}$ than W1 and W4 profiles.

PCA was carried out with the aim of studying the relationship between TRS optical properties and texture profiling. The parameters used in PCA were: $\mu_{\mathrm{a}}$ and $\mu_{\mathrm{s}}$, in the 630-900 $\mathrm{nm}$ range, the mechanical properties of the pulp, the sensory scores of firm, crispy, juicy and mealy attributes and the weight loss during shelf life. Four PCs were selected explaining $85.5 \%$ of total variance (Fig. 5). In PC-1 $\mu_{\text {s v values }}$ were opposed to firmness and to $\mu_{\mathrm{a}} 630-690$, bound to chlorophyll absorption peak, which were also related to stiffness, $E_{\mathrm{f}}$, firm, crispy, and juicy. PC-1 had the highest value for $\mathrm{W} 3$ and the least for $\mathrm{W} 1$ and W4 profiles (Fig. 6) and it significantly increased from VL to VH classes for firm, crispy and juicy attributes and from $\mathrm{VH}$ to $\mathrm{VL}$ classes for mealiness (Fig. 7). In PC-2 $\mu_{\mathrm{a}} 690, \mu_{\mathrm{a}} 730, \mu_{\mathrm{a}} 830, \mu_{\mathrm{a}} 850$ and $\mu_{\mathrm{a}} 900$ were opposed to mealiness and weight loss in shelf life (Fig. 5). The least PC-2 score was observed for $\mathrm{W} 1$ and the highest for $\mathrm{W} 3$ profile (Fig. 6) and it was significantly lower in $\mathrm{L}$ and $\mathrm{M}$ intensity classes for firm and crispy, $\mathrm{L}$ intensity class for juicy and $\mathrm{H}$ and VH intensity classes for mealy (Fig. 7).

PC-3 related $\mu_{\mathrm{a}} 730-900$ to weight loss during shelf life and in a weaker way to $E_{f}$; opposed to these parameters there were $\mu^{\prime}{ }_{\mathrm{s}} 630-690$ and $\mu{ }_{\mathrm{s}} 830-900$ which were related to firmness and stiffness (Fig. 5). This function did not significantly depend on the W1-W4 sensory profiles (Fig. 6) and on intensity classes for mealy and juicy, whereas it was significantly higher in $V L$ intensity class for firm and crispy (Fig. 7). PC-4 opposed crispy, firm and juicy to mealy and $\mu_{\mathrm{a}} 630-690$ (Fig. 5) and its value was significantly different among the sensory profiles, with the W3 one showing the highest score and the W1 the least (Fig. 6).
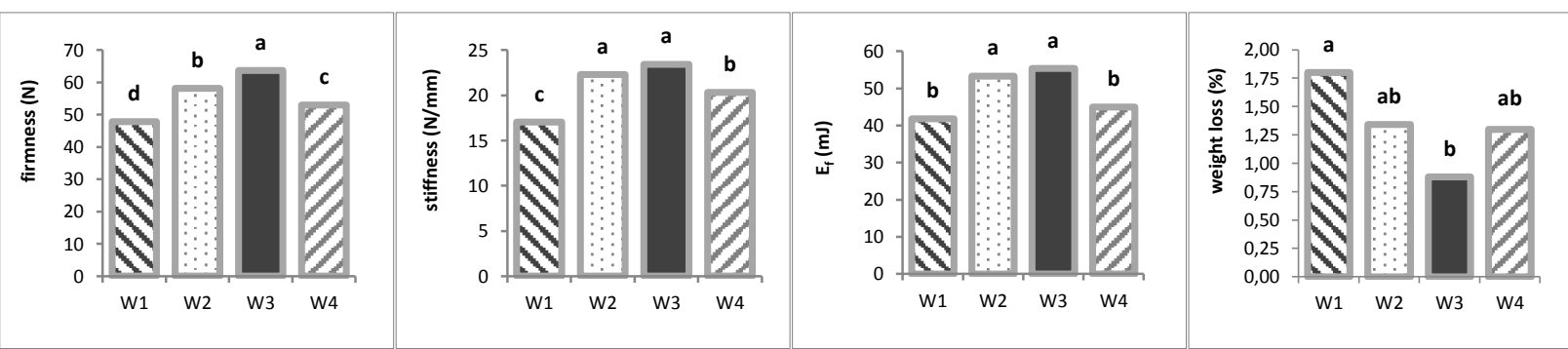

Fig. 4. Firmness, stiffness, energy-to-rupture $\left(E_{\mathrm{f}}\right)$ and weight loss during shelf life of apples grouped in the W1 to W4 sensory profiles. For each parameter bars with different letters are statistically different (Bonferroni's test, $\mathrm{p} \leq 0.05$ ) 

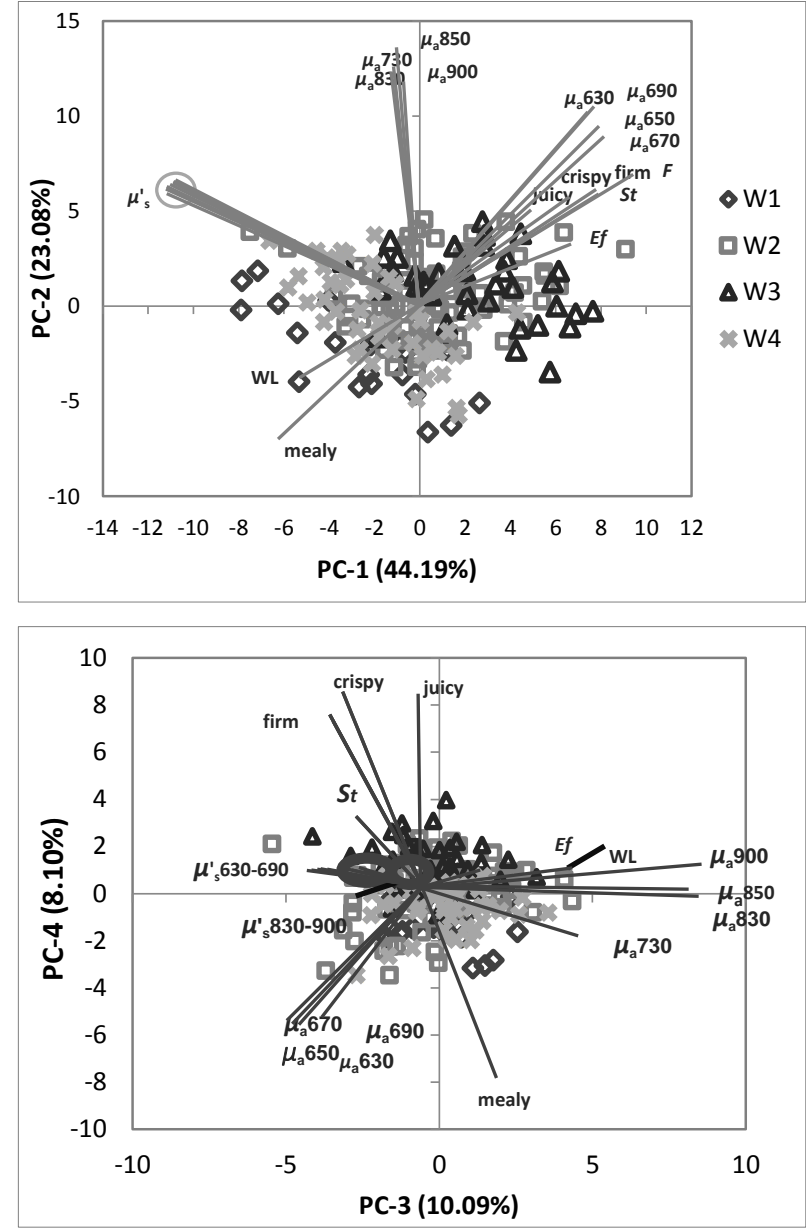

Fig. 5. PCA of TRS optical properties and texture profiling: biplots of PC-1 vs PC-2 (top) and PC-3 vs. PC-4 (bottom)
In addition PC-4 significantly increased from VL to VH classes for crispy, juicy and mealy attributes and was higher in $\mathrm{M}, \mathrm{H}$ and $\mathrm{VH}$ classes respect to $\mathrm{VL}$ and $\mathrm{L}$ ones for firm (Fig. 7).

Our results confirm the close relationship between the texture sensory profiling of stored apples, the pulp mechanical characteristics and their optical properties. In fact the apples clustered under profiles W1 (very mealy) and W4 (mealy) had lower $\mu_{\mathrm{a}} 670$ than fruit clustered under profiles W3 (very firm and very crispy) and W2 (firm/crispy/juicy); concomitantly scattering increased from the very firm and very crispy apples (W3) to the firm/crispy/juicy (W2) and to the very mealy (W1) and mealy (W4) ones. This pattern of optical properties indicates that in very mealy and mealy apples there is a more advanced chlorophyll breakdown and a higher density of scatterers proper of more mature apples (Vanoli et al. 2011).

Furthermore PCA underlined the close relationship between $\mu_{\mathrm{a}} 630-690$ (chlorophyll peak) with firmness and stiffness, crispy, juicy and mealy attributes, the negative correlation between $\mu_{\mathrm{a}} 830$ 900 (near to water absorption peak) and mealy attribute and weight loss during shelf life, as well as the inverse relationship of $\mu_{\text {s }}$ with pulp mechanical properties, firm, crispy and juicy attributes, confirming the findings reported by Rizzolo et al. (2010) and Vanoli et al. (2010).

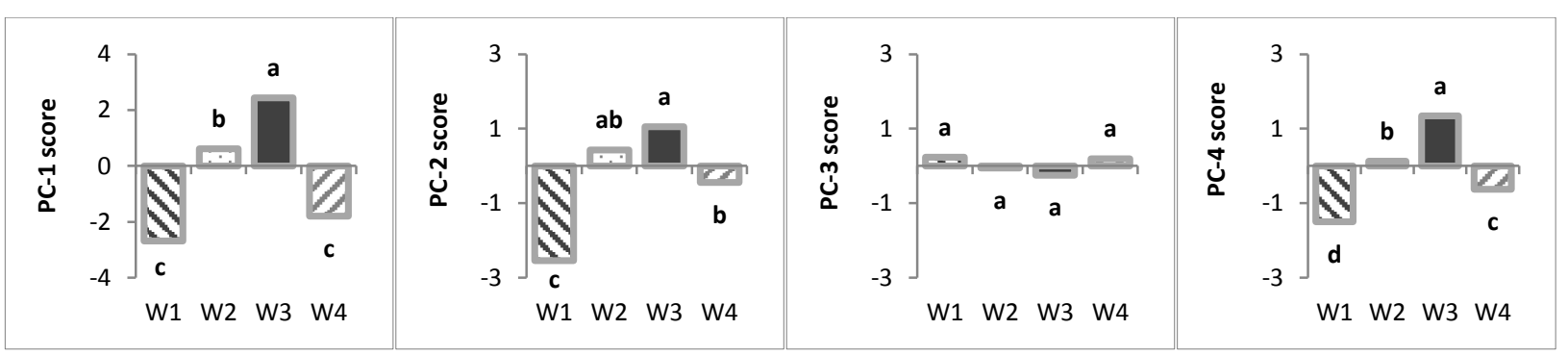

Fig. 6. PC scores for sensory profiles W1 to W4. Bars with different letters are statistically different (Bonferroni's test, $\mathrm{p} \leq 0.05)$ 


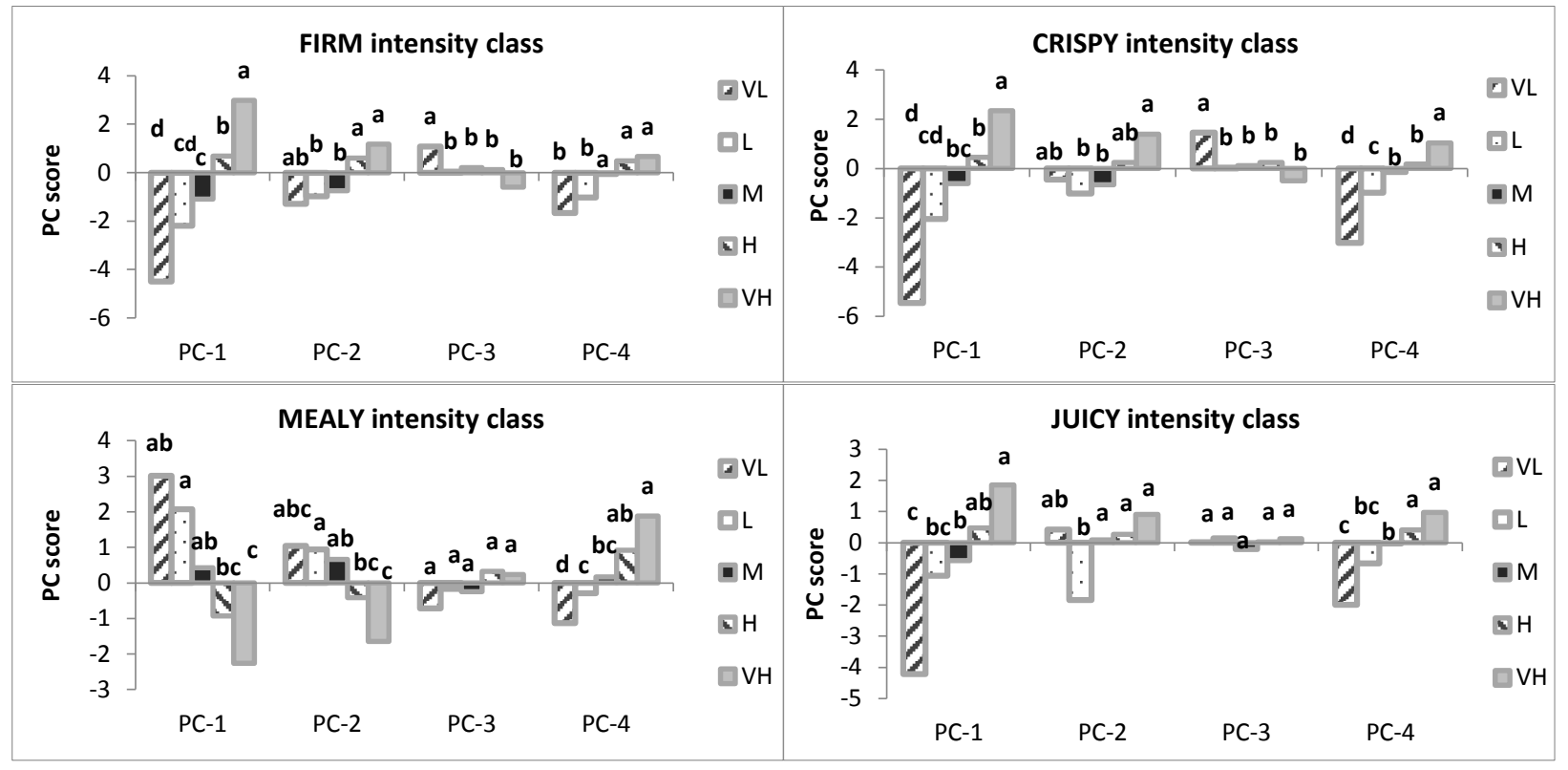

Fig. 7. PC scores in function of firm, crispy, mealy and juicy intensity classes. Bars with different letters are statistically different (Bonferroni's test, $\mathrm{p} \leq 0.05$ )

\section{REFERENCES}

Bianchi G., Eccher Zerbini P., Rizzolo A. 2009. Shortterm training and assessment for performance of a sensory descriptive panel for the olfactometric analysis of aroma extracts. J. Sens. Stud. 24: 149165. DOI: 10.1111/j.1745-459X.2008.00200.x.

Chen L., Opara U.L. 2013. Texture measurement approaches in fresh and processed foods. A review. Food Res. Int. 51: 823-835. DOI: 10.1016/j.foodres.2013.01.046.

Cubeddu R., D’Andrea C., Pifferi A., Taroni P., Torricelli A., Valentini G. et al. 2001. Time-resolved reflectance spectroscopy applied to the non-destructive monitoring of the internal optical properties in apples. Appl. Spectrosc. 55: 1368-1374.

Huang M., Zhu Q., Wang B., Lu R. 2012. Analysis of hyperspectral scattering images using locally linear embedding algorithm for apple mealiness classification. Comput. Electron. Agric. 89: 175181. DOI: 10.1016/j.compag.2012.09.003.

Martelli F., Del Bianco S., Ismaelli A., Zaccanti G. 2009. Light propagation through biological tissue and other diffusive media: theory, solutions and software. SPIE, Washington, USA.

Mehinagic E., Royer G., Bertrand D., Symoneaux R., Laurens F., Jourjon F. 2003. Relationship between sensory analysis, penetrometry and visible-NIR spectroscopy of apple belonging to different cultivars. Food Qual. Prefer. 14: 473-484. DOI: 10.1016/S0950-3293(03)00012-0.

Mehinagic E., Royer G., Symoneaux R., Bertrand D., Jourjon F. 2004. Prediction of the sensory quality of apples by physical measurements. Postharvest Biol. Technol. 34: 257-269. DOI: 10.1016/j.postharvbio.2004.05.017.

Rizzolo A., Vanoli M., Spinelli L., Torricelli A. 2010. Sensory characteristics, quality and optical properties measured by time-resolved reflectance spectroscopy in stored apples. Postharvest Biol. Technol. 58: 1-12. DOI: 10.1016/j.postharvbio.2010.05.003.

Saeys W., Velazco-Roa M.A., Thennadil S.N., Ramon H., Nicolaï B.M. 2008. Optical properties of apple skin and flesh in the wavelength range from 350 to $2200 \mathrm{~nm}$. Appl. Opt. 47: 908-919. DOI: 10.1364/AO.47.000908.

Szczesniak A.S. 2002. Texture is a sensory property. Food Qual. Prefer. 13: 215-225. DOI: 10.1016/S0950-3293(01)00039-8.

Torricelli A., Spinelli L., Contini D., Vanoli M., Rizzolo A., Eccher Zerbini P. 2008. Time-resolved reflectance spectroscopy for non-destructive assessment of food quality. Sens. Instrum. Food Qual. Saf. 2: 82-89. DOI: 10.1007/s11694-008-9036-2. 
Valero C., Barreiro P., Ruiz-Altisent M., Cubeddu R., Pifferi A., Taroni P. et al. 2005. Mealiness detection in apples using time-resolved reflectance spectroscopy. J. Texture Stud. 36: 439-458. DOI: 10.1111/j.1745-4603.2005.00026.x.

Vanoli M., Zerbini P.E., Rizzolo A., Spinelli L., Torricelli A. 2010. Time-resolved reflectance spectroscopy for the non-destructive detection of inner attributes and defects of fruit. Acta Hort. 877: 1379-1386.

Vanoli M., Rizzolo A., Grassi M., Farina A., Pifferi A., Spinelli L., Torricelli A. 2011. Time-resolved reflec- tance spectroscopy non-destructively reveals structural changes in 'Pink Lady ${ }^{\circledR}$ ' apples during storage. Procedia Food Sci. 1: 81-89. DOI: 10.1016/j.profoo.2011.09.014.

Vanoli M., Rizzolo A., Zanella A., Grassi M., Spinelli L., Cubeddu R., Torricelli A. 2013. Apple texture in relation to optical, physical and sensory properties. Proceedings "InsideFood Symposium”, Leuven, Belgium. www.insidefood.eu/INSIDEFOOD_WEB/UK/WORD/proceedings/032P.pdf 